\title{
Cyclone impact on sea ice in the central Arctic Ocean: a statistical study
}

\author{
A. Kriegsmann ${ }^{1, *}$ and B. Brümmer ${ }^{1}$ \\ ${ }^{1}$ Meteorological Institute, University of Hamburg, Hamburg, Germany \\ *now at: Climate Service Center, Hamburg, Germany
}

Correspondence to: A. Kriegsmann (arne.kriegsmann@zmaw.de)

Received: 9 January 2013 - Published in The Cryosphere Discuss.: 21 March 2013

Revised: 22 November 2013 - Accepted: 6 January 2014 - Published: 27 February 2014

\begin{abstract}
This study investigates the impact of cyclones on the Arctic Ocean sea ice for the first time in a statistical manner. We apply the coupled ice-ocean model NAOSIM which is forced by the ECMWF analyses for the period 2006-2008. Cyclone position and radius detected in the ECMWF data are used to extract fields of wind, ice drift, and concentration from the ice-ocean model. Composite fields around the cyclone centre are calculated for different cyclone intensities, the four seasons, and different sub-regions of the Arctic Ocean. In total about 3500 cyclone events are analyzed. In general, cyclones reduce the ice concentration in the order of a few percent increasing towards the cyclone centre. This is confirmed by independent AMSR-E satellite data. The reduction increases with cyclone intensity and is most pronounced in summer and on the Siberian side of the Arctic Ocean. For the Arctic ice cover the cumulative impact of cyclones has climatologic consequences. In winter, the cyclone-induced openings refreeze so that the ice mass is increased. In summer, the openings remain open and the ice melt is accelerated via the positive albedo feedback. Strong summer storms on the Siberian side of the Arctic Ocean may have been important contributions to the recent ice extent minima in 2007 and 2012.
\end{abstract}

\section{Introduction}

Arctic sea-ice extent and thickness have undergone a significant decline in the last decade (Stroeve et al., 2012) with the latest record sea-ice extent minimum in September 2012. The reasons are manifold and cannot be assigned to one process only. However, it is generally accepted that the decline is also a signature of anthropogenic climate change (e.g. Notz and Marotzke, 2012).

Although sea ice is finally the result of local thermodynamic freezing and melting, there are many processes that significantly influence sea-ice formation and destruction. To this end, cyclones play an important role with both thermodynamic and dynamic aspects. With respect to the thermodynamics, cyclones contribute the major part of the sensible heat and moisture advection to the Arctic (e.g. Overland and Turet, 1994). In addition, the related higher amount of clouds enhances the surface radiation and energy budget in autumn through spring and reduces it in summer (e.g. Curry et al., 1993; Intrieri et al., 2002). With respect to the dynamics, the strong, inhomogeneous wind field in cyclones deforms the ice cover and causes cracks, leads and polynias. The effect of these openings is different in winter and summer. In winter, the openings are the places with the largest heat fluxes from the ocean to the atmosphere. The openings refreeze so that the heat fluxes decrease with time and salt is released from the newly formed ice to the ocean. In summer, refreezing does not occur, so that almost all downwelling short-wave radiation is absorbed. This leads to a local warming of the uppermost ocean layer and promotes further ice melt (e.g. Perovich et al., 2008).

The potential of cyclones to significantly affect the sea ice has been demonstrated in many case studies. Zwally and Walsh (1987) investigated by means of satellite images and model data the local change in ice concentration under the influence of a wintertime cyclone north of Alaska. Even though the impact of the wind field of the cyclone lasted only between 1 and 3 days, the reduction of the multiyear sea ice persisted for months. With satellite data and ice-drift buoy 
measurements Maslanik and Barry (1989) found for wintertime situations in the Canadian part of the central Arctic, that cyclones lead to reductions in sea-ice concentration and increased divergence of the sea-ice drift. Barry and Maslanik (1989) also reported a reduction in sea-ice concentration in summer in the Canadian part of the Arctic, caused by cyclonic conditions in the wind field and the associated divergent and sheared ice drift. In the western Arctic, a strong cyclone reduced the sea-ice concentration by 3 to $5 \%$ in October 1991 (Maslanik et al., 1995). A measured increase in the fraction of first year ice was attributed to the freezing of the cyclone-induced open water areas.

Through the breaking of the ice cover, internal stress within the ice is reduced and the mobility of the ice floes is increased. The ratio of ice-drift speed and wind speed (the wind factor) is increased for a short time period after the cyclone passage (Brümmer and Hoeber, 1999). On the basis of satellite images, Holt and Martin (2001) investigated the passage of a cyclone through the Beaufort Sea, the Chukchi Sea, and the East Siberian Sea in August 1992. They reported a growth of the fraction with open water and a decrease in the size of floes. Using RADARSAT satellite images, Brümmer et al. (2008) analyzed the ice-drift field around a cyclone in March 2002. They found a divergent drift in the centre of the cyclone and a convergent drift at the margins.

On the basis of buoy measurements, Brümmer et al. (2003) found cyclone-induced inertial oscillations or tidal oscillations in the Fram Strait. They showed, that the oscillations are also detectable in the divergence, the vorticity and the deformation of the ice drift. Lammert et al. (2009) reported on a cyclone that caused a resonant forcing of inertial oscillations of the sea ice in the Fram Strait in March 2007. On the right side of the cyclone track (looking along the propagation vector) the wind direction changes were in phase with the drift direction changes of the inertial oscillation so that the ice concentration was reduced by up to $11 \%$.

More process-oriented, Haapala et al. (2005) used a multicategory sea-ice model in order to separate sea ice in "undeformed" and "deformed" ice classes. In model simulations with a prescribed cyclone propagating over ice, they investigated how the amount of the open water forming through the deformation influence of the cyclone depends on the chosen cyclone and ice parameters. Kawaguchi and Mitsudera (2008) used a Lagrangian ice model with an idealized stationary cyclone to examine mechanisms that cause ice divergence and its seasonal changes. They found, among other factors, that even the stratification of the ocean between winter and summer can change the ice divergence by a factor of 2. This is because the divergence of the Ekman flow in the shallow, stable ocean boundary layer below the ice in summer is larger than in the deeper and less stable boundary layer in winter.

Based on reanalysis data, Simmonds and Rudeva (2012) investigated a strong Arctic cyclone that occurred during August 2012. While their paper focuses mainly on the properties of the cyclone, they also note, that the cyclone led to a dispersion and separation of a significant amount of ice from the main Arctic ice shield.

Screen et al. (2011) investigated the relationship between sea-ice extent at the end of the Arctic summer, and cyclone activity in the preceding spring and summer. They found that fewer cyclones over the central Arctic Ocean in May, June, and July favour a low sea-ice extent at the end of the melt season. They argue that fewer storms are associated with above-average sea-level pressure, strengthened anticyclonic winds, intensification of the transpolar drift stream, and reduced cloud cover, which all favor ice melt.

In this paper, we use a statistical approach to quantify the local impact of cyclones on the sea ice in the Arctic Ocean, applying a combination of observations and modelling. We use the six-hourly operational analyses of the ECMWF (European Centre for Medium-Range Weather Forecasts) as atmospheric forcing of the coupled ice-ocean model NAOSIM (North Atlantic-Arctic Ocean Sea-Ice Model). Within a certain radius around the cyclone position the model-simulated impact on the sea ice is determined with respect to ice concentration and the wind-ice-drift relation. The model results for the individual cyclone cases are stratified by different cyclone intensities, different seasons, and different sub-regions of the Arctic Ocean. For all classes, the spatial distribution of wind, drift, and ice concentration within the cyclone radius and the time evolution from before, during, to after the cyclone event are investigated. The study is based on a threeyear period 2006-2008, thus, including the time of the sofar second-lowest summer ice extent minimum in September 2007.

The paper is organized as follows: Sect. 2 describes the model, the model domain, and the study area. Section 3 details the method of cyclone detection. The results of the statistical analyses of the impact of the cyclones on sea ice in the central Arctic Ocean are presented in Sect. 4 with respect to the cyclone intensity, to seasonal differences, and to regional differences. Conclusions are given in Sect. 5.

\section{The ice-ocean model}

The model NAOSIM is a coupled sea-ice-ocean model. It has been applied in many research papers (e.g. Köberle and Gerdes, 2003; Karcher et al., 2007; Rozman et al., 2011) and also participated in the Arctic Ocean Model Intercomparison Project (e.g. Martin and Gerdes, 2007). The ocean part is based on the Modular Ocean Model 2 of the Geophysical Fluid Dynamics Laboratory. The sea-ice part is the dynamic-thermodynamic ice model based on the work of Hibler (1979), and was enhanced, for example, in the subgrid sea-ice thickness (Hibler, 1984) and in the rheology (Harder, 1996). The sea ice follows a viscous-plastic rheology. The prognostic variables of the ice model are ice concentration and thickness, snow height, and ice drift. On a subgrid scale, 


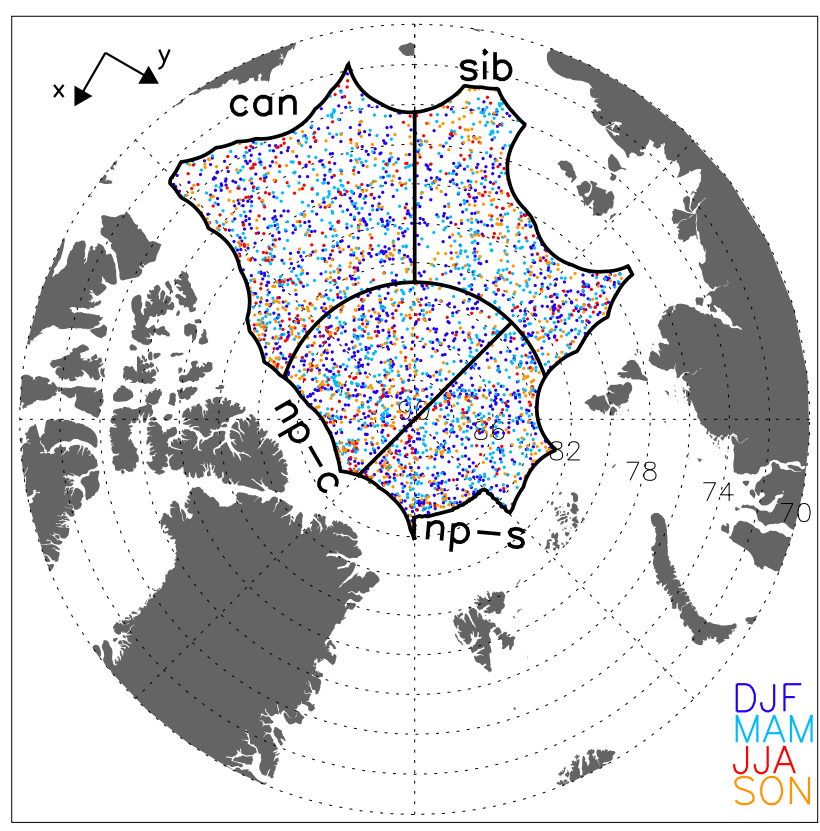

Fig. 1. Study area with spatial and seasonal distribution of the cyclone detections (dots) for the period 2006-2008. The orientation of the $(x, y)$ coordinate axes is shown in the upper left corner.

the thermodynamic ice thickness growth is distinguished between seven ice thickness classes. The model domain covers the whole Arctic and the North Atlantic with a southern border at the $50^{\circ} \mathrm{N}$ latitude line. The $x$ axis is parallel to the $30^{\circ} \mathrm{W} / 150^{\circ} \mathrm{E}$ longitude line. Since the impact of the coast on the ice drift is detectable up to several hundred kilometres (Thorndike and Colony, 1982), we restrict our studies to those parts of the Arctic Ocean that are at least $300 \mathrm{~km}$ distant from the nearest coast (Fig. 1). The spatial resolution is $\approx 9 \mathrm{~km}$. The model time step is $5 \mathrm{~min}$ and the prognostic ice variables were stored every $3 \mathrm{~h}$. The model needs a prescribed atmosphere every $6 \mathrm{~h}$. In this work, forcing data of the ECMWF operational analysis are used. These data have a spatial resolution of $25 \mathrm{~km}$ and are interpolated to the $9 \mathrm{~km}$ model grid. The forcing variables are temperature, dew point temperature, wind, cloud cover, and precipitation. Precipitation is taken from ECMWF $6 \mathrm{~h}$ forecast. The short-wave and long-wave up- and downwelling radiation fluxes are parameterized in the NAOSIM model as well as the turbulent fluxes of momentum and sensible and latent heat.

Since the cyclone impact on sea ice is taken here from the NAOSIM model, the degree of realism of the results depends essentially on the model quality. The quality of NAOSIM with respect to ice drift has been tested against satellite and in-situ data in several publications (e.g. Martin and Gerdes, 2007; Rozman et al., 2011). The results show a high correlation of at least 0.84 between the simulated drift and the in situ data. The standard deviation of the error for the model simulations validated with mooring observations amounts to
$0.03 \mathrm{~m} \mathrm{~s}^{-1}$. Results from comparisons between the model simulations during the period 2006-2008 in this paper and simultaneous buoy drift data are presented in Kriegsmann (2011). The data were taken from two ice-drift experiments with 16 buoys in the region north of $85^{\circ} \mathrm{N}$ for the period April 2007-January 2008 and with eight buoys in the American sector of the Arctic for the period April 2008-February 2009. For both drift experiments, model-buoy correlations for both the $\mathrm{u}$ - and v-ice-drift component were between 0.82 and 0.85 . In general, there were more model overestimations for ice drifts $<0.2 \mathrm{~m} \mathrm{~s}^{-1}$ and underestimations for ice drifts $>0.2 \mathrm{~m} \mathrm{~s}^{-1}$, that is, model variability was less than observed variability. The angle difference varies around zero, but with more positive than negative deviations. The angle difference for each buoy averaged over the lifetime of the buoy is between $3^{\circ}$ and $19^{\circ}$ to the right of the buoy drift. It should be mentioned that the model-buoy differences cannot solely be attributed to the model, but can result also from uncertainties of the ECMWF analysis and to a minor degree from measurement errors.

For our study, there might have been the option to use satellite-derived fields of ice motion. However, even the best time resolution of 1 day (mean over 1 day) and spatial resolution of $25 \mathrm{~km}$ appear not yet adequate for a cyclone impact study which requires simultaneous fields of atmosphere and ice with high time and spatial resolution as applied in this paper.

In order to compare the cyclone-induced changes in ice concentration between model and observations, we use the satellite-based AMSR-E (Advanced Microwave Scanning Radiometer - Earth Observing System) microwave ( $89 \mathrm{GHz}$ ) sea-ice concentration, retrieved with the ASI-algorithm. The satellite data were obtained from the Integrated Climate Data Center (ICDC, http://icdc.zmaw.de), University of Hamburg, Germany. The AMSR-E ice concentration data have a horizontal resolution of $6.5 \mathrm{~km}$ and a time resolution of 1 day. For the comparison, the AMSR-E data are interpolated to the $9 \mathrm{~km}$ model grid. AMSR-E has the tendency to overestimate the ice concentration (Spreen et al., 2008). This is mainly the case in summer so that the ice-covered area in the simulation and from the AMSR-E data do not match well (Fig. 2). Therefore, all cyclone cases with a difference in the mean ice concentration within the cyclone radius (for definition, see Sect. 3) of more than $10 \%$ are neglected for the cyclone impact study (called ADiff-Filter). The ADiff-filter removes about $30 \%$ of the cyclone detection cases (Table 1). It should be mentioned that in this study we are only interested in changes of ice concentration, not in the absolute values.

\section{Cyclone detection}

Cyclone position, radius, and intensity are determined from the 6-hourly sea level pressure field of the ECMWF analysis for the period 2006-2008 applying the algorithm of Murray 

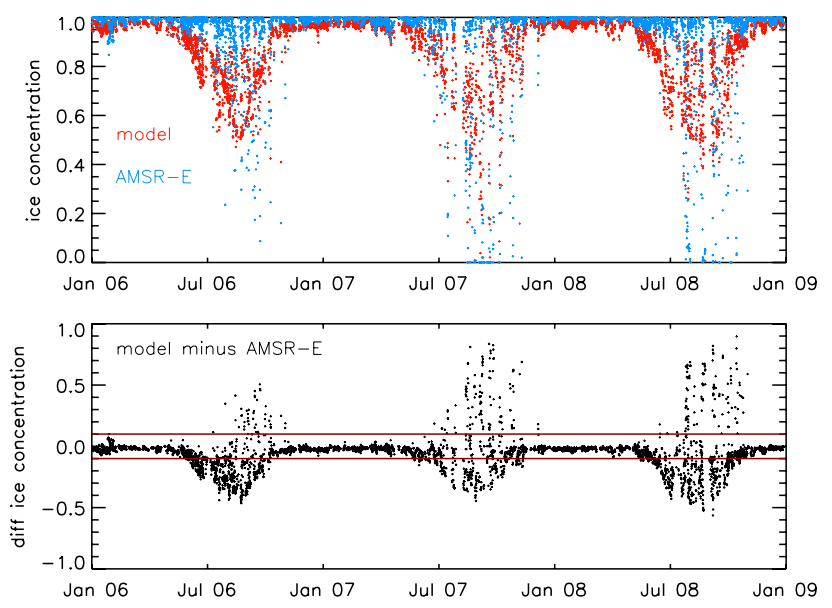

Fig. 2. Top: mean simulated and AMSR-E ice concentration within the cyclone radius for all 5057 detections. Bottom: difference between mean simulated and AMSR-E ice concentration. Red line marks range of Adiff-filter.

and Simmonds (1991). In the beginning, the first and the second derivatives of the two-dimensional field of sea level pressure $p$ are calculated at all grid points. Grid points where the Laplace operator $\nabla^{2} p=p_{x x}+p_{y y}$, which is proportional to the geostrophic vorticity, has a local maximum and is above a certain threshold are candidates for a cyclone. In the case that a pressure minimum in the surrounding of this point exists, the exact position of the cyclone core is calculated. The cyclone detection according to Murray and Simmonds (1991) depends on many settings, for example on the threshold of $\nabla^{2} p$, on the search radius around the maximum of the Laplace operator, on the search area and the kind of search. For cyclone tracking, the detections are connected to cyclone tracks, based on probability calculations regarding cyclone track direction, cyclone speed, and core pressure among others.

In this work, two further quantities are used in addition to position and time of detection: the radius and the intensity of a cyclone. The radius is defined as a weighted distance (weighted over 12 directions) between core and margin of a cyclone, where margin is the place with $\nabla^{2} p=0$. The intensity of a cyclone is defined as the mean of $\nabla^{2} p$ within the radius region.

The cyclone data set which we use was prepared by Haller (2011) and contains all detections for the area north of $60^{\circ} \mathrm{N}$, for the period 2006-2008. This amounts to a total of 70405 detections belonging to 7987 cyclones (Table 1). On average, each cyclone has 8.8 detections (i.e. a lifetime of about $53 \mathrm{~h}$ ). Detections in the study area after applying the Adiff-filter amount to 3496 detections belonging to 692 cyclones.

The automated detection of cyclones is an often applied method. For example, Jahnke-Bornemann (2010) uses an automated procedure of Blender et al. (1997) for investigations of cyclones in the Norwegian Sea. Also with an automated
Table 1. Number of detections (cyclones).

\begin{tabular}{cccc}
\hline & North of $60^{\circ} \mathrm{N}$ & Within study area & After ADiff-filter \\
\hline 2006 & $23220(2627)$ & $1874(316)$ & $1245(248)$ \\
2007 & $23171(2570)$ & $1462(248)$ & $1100(204)$ \\
2008 & $24014(2790)$ & $1721(304)$ & $1151(240)$ \\
\hline Total & $70405(7987)$ & $5057(868)$ & $3496(692)$ \\
\hline
\end{tabular}

procedure, Serreze and Barrett (2008) found in reanalyses of the National Centers for Environmental Prediction (NCEP) in the long-time mean a maximum of cyclones in the central Arctic during the summer. Affeld (2003) used automatically detected cyclones to investigate the impact of cyclones on the ice transport through the Fram Strait. A good review of the different approaches to detect (and track) cyclones is given in Ulbrich et al. (2009).

On the basis of the position of the cyclones the mean impact on ice concentration and ice drift was investigated. The cyclone detections were sorted into different classes in order to find out how the impact of the cyclone on the sea ice varies with cyclone intensity, season, and sub-region of the Arctic Ocean.

The study period 2006-2008 contains the time (September 2007) when the so-far second lowest summer ice-extent minimum occurred. The cyclone frequency during this period was at an almost constant level, embedded in an otherwise increasing trend of cyclone frequency since 1958 (Haller, 2011). In terms of general circulation, characterized by North Atlantic Oscillation and Arctic Oscillation indices (e.g.http:// www.ersl.noaa.gov/psd/gcos_wgsp/Timeseries), this period was not particularly outstanding. So, our results can be regarded to represent Arctic conditions typical for the first decade of the 21th century.

\section{Statistical analysis of cyclone impact on sea ice}

In this section the impact of cyclones on the Arctic Ocean sea ice is presented and distinguished with respect to three categories. The first category is the strength of the atmospheric forcing which we assume to be represented by the cyclone intensity. The second category is the season because in addition to, for example, different air temperatures, a cyclone meets different sea-ice conditions such as concentration, thickness, or ice strength and, thus, the consequences on the different sea ice are expected to be different. The third category is the sub-region of the Arctic Ocean because the sea ice has a distinct gradient, for example, in thickness from the Siberian (thin) to the Canadian side (thick) and belongs to different drift regimes (Transpolar Drift, Beaufort Gyre).

Each category (intensity, season, region) is subdivided into four classes. For each class composite fields for wind, ice drift and concentration around the cyclone are calculated. This is performed in a relative horizontal coordinate frame 
which has its origin at the cyclone centre and is normalized with the cyclone radius. The composite averaging is made without any rotation of the frame (e.g. with respect to North). So, the relative $x, y$ frame in the figures below is parallel to the axes of the model domain (see Fig. 1) and $x=y=1$ is the normalized cyclone radius.

\subsection{Cyclone intensity}

The intensity $I=\nabla^{2} p$ of all cyclone detections in the study area during the period 2006-2008 ranges from $I=0$ to $I=$ $I_{\max }\left(=7.31 \mathrm{hPa}(\text { deg.lat. })^{-2}\right)$. We distinguish between four intensity classes, $I_{1}$ to $I_{4}$, belonging to the four quartiles of the frequency distribution. The intensity range for each class together with the average cyclone radius is given in Table 2.

For each class the mean wind vector field and the mean wind speed are shown in Fig. 3 (top). The cyclonic structure of the wind field does not end at the cyclone radius, but reaches to twice the cyclone radius. As expected, the wind speed increases with increasing intensity. The maximum mean wind speed increases from about $4 \mathrm{~m} \mathrm{~s}^{-1}$ in $I_{1}$ to almost $9.5 \mathrm{~m} \mathrm{~s}^{-1}$ in $I_{4}$. The wind speed slows down towards the cyclone centre where it is around $2.5 \mathrm{~m} \mathrm{~s}^{-1}$ in $I_{1}$ and $4.5 \mathrm{~m} \mathrm{~s}^{-1}$ in $I_{4}$.

The wind fields in Fig. 3 are not rotationally symmetric but show the highest winds and, thus, the strongest pressure gradients in the direction towards the negative $x$ and $y$ directions. This is (see Fig. 1) along the direction from the North Atlantic side to the Pacific side of the Arctic Ocean, and coincides with the gradient of the climatologically mean sea-level pressure distribution which exhibits lower pressure over the northeast Atlantic and higher pressure over the East Siberian Sea and Beaufort Sea (e.g. Serreze and Barry, 2005). If a symmetric cyclone pressure field is superposed to this climatological pressure distribution the resulting pressure gradient in the cyclone is stronger on the side towards the climatological high pressure than towards the low pressure.

The mean ice-drift field in Fig. 3 (bottom) has a similar cyclonic structure as the wind field. The ice drift decreases towards the centre in accordance with the decreasing wind. This is true for all intensity classes.

The relation between drift and wind is presented in Fig. 4 by means of the wind factor WF (ratio drift vs. wind) and the deviation angle DA (positive for ice drift to the right of the wind). WF and DA are relatively easily accessible from observations and are frequently applied in the literature because they are indirect indicators for the importance of the individual forces in the ice momentum balance equation. In case of a free ice drift (internal ice force negligible which is typically assumed for ice concentrations below 0.8, Leppäranta, 2005, p. 141) and thin ice (Coriolis force negligible), the WF is the square root of the ratio of the products of density and drag coefficient in atmosphere and ocean. If, in addition, the ocean current is zero the ice drifts along the wind. If we as-
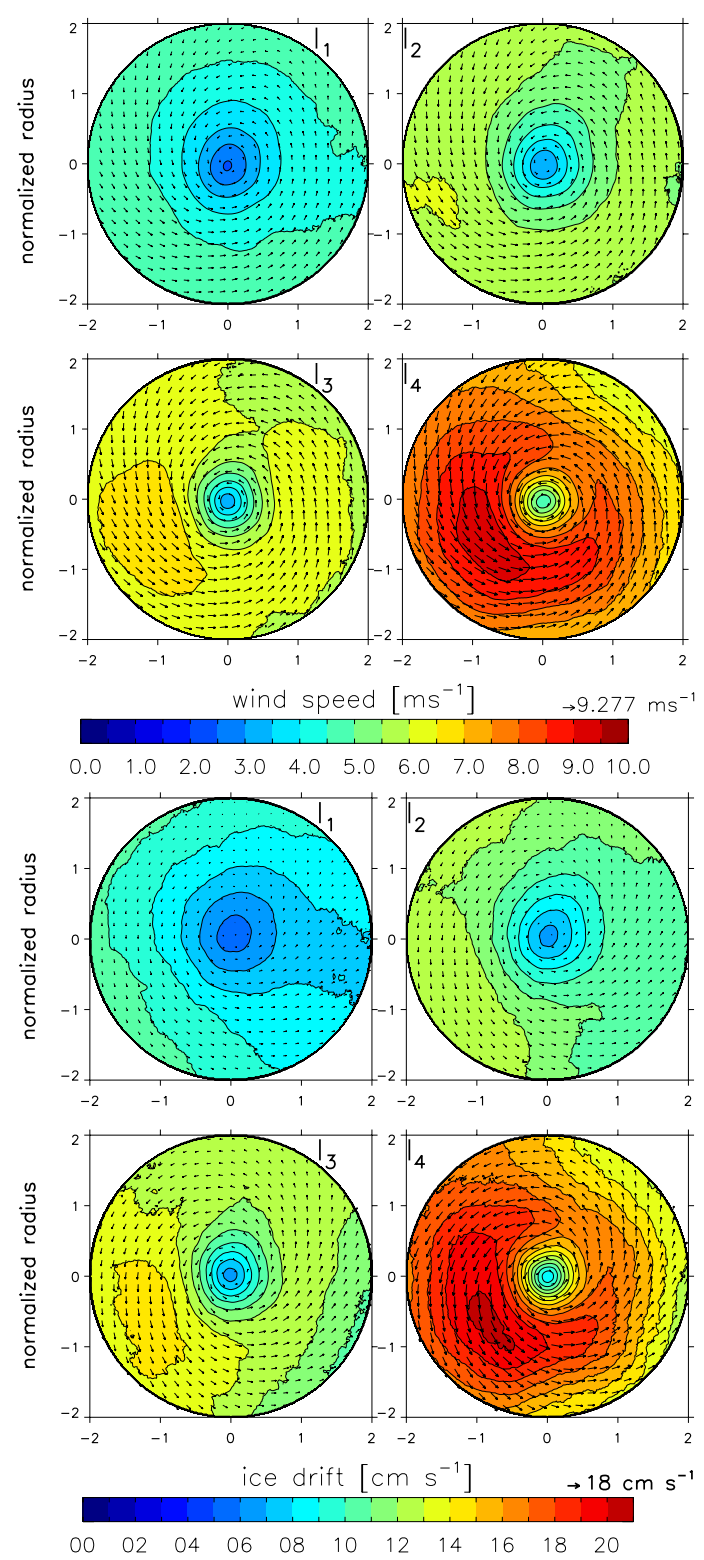

Fig. 3. Mean wind (top) and mean ice drift (bottom) for the intensity classes $I_{1}$ to $I_{4}$, centred on the location of the cyclone detection and normalized with the cyclone radius. Mean vectors as arrows, mean over absolute value of the speed as color. Isoline interval is $0.5 \mathrm{~m} \mathrm{~s}^{-1}$ for wind speed and $1 \mathrm{~cm} \mathrm{~s}^{-1}$ for ice drift.

sume a wind-driven Ekman current in the ocean the ice drifts to the right of the wind and to the left of the current. With increasing ice thickness (i.e. increasing Coriolis force), the WF decreases and the DA increases (Leppäranta, 2005, p. 144). In case of ice concentrations above 0.8 , the internal ice force has to be taken into account. It is about opposite to the drift and acts towards a decrease of WF and DA (Thorndike and Colony, 1982). The inertial force is typically small but can modify these relations for example if rapid wind changes occur. 
Table 2. Number of cyclone detections with corresponding mean radius and intensity for intensity quartiles, seasons, and regions.

\begin{tabular}{|c|c|c|c|c|c|c|c|c|c|c|}
\hline $\begin{array}{l}\text { Intensity } \\
\left(\% \text { of } I_{\max }\right)\end{array}$ & No. & $\begin{array}{c}\text { Radius } \\
\text { [km] }\end{array}$ & Season & No. & $\begin{array}{r}\text { Radius } \\
{[\mathrm{km}]}\end{array}$ & $\begin{array}{c}\text { Intensity } \\
\text { hPa (deg.lat.) }\end{array}$ & Region & No. & $\begin{array}{r}\text { Radius } \\
{[\mathrm{km}]}\end{array}$ & $\begin{array}{c}\text { Intensity } \\
\mathrm{hPa}(\text { deg.lat. })^{-2}\end{array}$ \\
\hline$I_{1}(0-14.7)$ & 873 & 266 & winter & 1360 & 315 & 1.76 & $\mathrm{np}-\mathrm{s}$ & 782 & 298 & 1.95 \\
\hline$I_{2}(14.7-20.3)$ & 875 & 306 & spring & 1067 & 320 & 1.73 & $n p-c$ & 844 & 309 & 1.69 \\
\hline$I_{3}(20.3-29.0)$ & 874 & 327 & summer & 374 & 303 & 1.64 & sib & 789 & 316 & 1.70 \\
\hline$I_{4}(29.0-100)$ & 874 & 344 & autumn & 694 & 293 & 1.75 & can & 1080 & 318 & 1.58 \\
\hline
\end{tabular}

Averaging the WF and DA over the area within the double cyclone radius and over all cyclone detections and all intensities, they amount to about $2.0 \%$ and $30^{\circ}$, respectively. This agrees with the values cited by Leppäranta (2005, p. 144) as typical for the Arctic Ocean. This is again an indirect indication for the validity of the NAOSIM model and that the above-mentioned (Sect. 2) differences found between model and drift buoys cannot be attributed to model alone. For all intensities, Fig. 4 exhibits a mean gradient in the WF and DA composite fields: WF (DA) decreases (increases) towards the positive $x$ direction and weakly negative $y$ direction. This direction points from the Siberian side to the Canadian side (i.e. from thinner to thicker ice). These mean gradients in Fig. 4 agree with the above-mentioned increasing influence of the Coriolis force with increasing ice thickness. These gradients remain, even in the case of ice concentrations above 0.8 , when the internal ice stress has to be regarded in the balance of forces.

The WF and DA values deviate from this gradient around the cyclone centre in a region with a non-dimensional radius of 0.25 to 0.5 . The DA minimum below $20^{\circ}$ and WF maximum of up to $2.6 \%$ are suggestive of a smaller ice thickness in the centre than on the perimeter. The WF maximum is almost absent in $I_{4}$ and increases with decreasing intensity. This may be related to the slowing down of the wind in the cyclone centre. At these weak winds the inertia of the ice drift and, in addition, the ocean current come into play and can make the WF particularly high (Leppäranta, 2005, p. 146).

Next we investigate the time development of wind and drift in the fixed circular area where the cyclone passes over (is detected) at $t=0$. We calculate composite fields every $3 \mathrm{~h}$ from 2 days before until 5 days after the cyclone passage. The horizontal averages of the composite fields of wind, ice drift, and wind factor WF within the cyclone radius are calculated and displayed in Fig. 5. Hereby, the mean WF is not calculated as ratio of mean ice drift and mean wind but as the mean of the individual ratios at each grid point. The ratio ice drift / wind can be arbitrarily high for small wind speed; therefore WF was only taken into account when the wind stress was at least $0.01 \mathrm{~N} \mathrm{~m}^{-2}$, that corresponds to a wind of about $1.8 \mathrm{~m} \mathrm{~s}^{-1}$.

The time series of the horizontally averaged wind speed show an opposite time development for the intensity classes
$I_{1}$ and $I_{4}$ with a minimum and a maximum near $t=0$ and $t=-0.25 \mathrm{~d}$, respectively. The different behaviour can be understood from the different wind fields in Fig. 3. In $I_{1}$, the wind speed increases from the centre to the single radius and remains relatively constant further outside. If such a cyclone approaches, the mean wind speed within the fixed circular area decreases the closer the cyclone is and becomes minimal around $t=0$, when the wind field including its minimum is centred over the fixed averaging area. The situation is different in $I_{4}$ : the wind speed has a distinct maximum around the cyclone radius, centred in the negative $(x, y)$ direction, and decreases towards both the centre and further outside. If such a cyclone approaches the fixed area, the mean wind first has to increase. $I_{2}$ and $I_{3}$ are transition classes between $I_{1}$ and $I_{4}$.

As expected, the time series of the ice drift are similar to those of the wind speed. The four time series of WF differ significantly only between the intensity classes $I_{1}$ and $I_{4}$ around $t=0$. There, surprisingly, WF exhibits a minimum and a maximum, respectively. A possible reason may be related to regional differences, because $I_{1}$-cyclones occur most frequently over the Canadian sector (Can) and $I_{4}$-cyclones over the North Pole sector on the Siberian side (NP-S) (see Fig. 1 and Table 2). This is further outlined in Sect. 4.3 on the regional differences.

In the following, the changes in ice concentration within $24 \mathrm{~h}$ after cyclone passage $(t=0)$ are displayed in Fig. 6 . For each intensity class a reduction in ice concentration around the cyclone centre is simulated. With increasing intensity, the area, where the ice concentration is reduced, becomes larger and the reduction becomes stronger. The change in the centre is at $-0.7 \%$ day $^{-1}$ in $I_{1}$ and at $-2.1 \%$ day $^{-1}$ in $I_{4}$.

For comparison, the $24 \mathrm{~h}$ ice concentration change based on AMSR-E is also shown in Fig. 6. It should be kept in mind that the time resolution of the AMSR-E ice concentration fields is 1 day and that a field is composed of several satellite orbits. For the calculation of the ice concentration change, we assume that the daily fields hold for 12 UTC and then interpolate the daily fields to the time of cyclone detection $(t=0)$ and to $t=24 \mathrm{~h}$. The $24 \mathrm{~h}$ change in the AMSR-E ice concentration shows no major difference between the $I_{1}$ to $I_{3}$. The ice concentration decreases in the cyclone centre by up to $-1 \%$ day $^{-1}$. The single radius area is surrounded by an area with ice concentration increase. In $I_{4}$, the reduction 

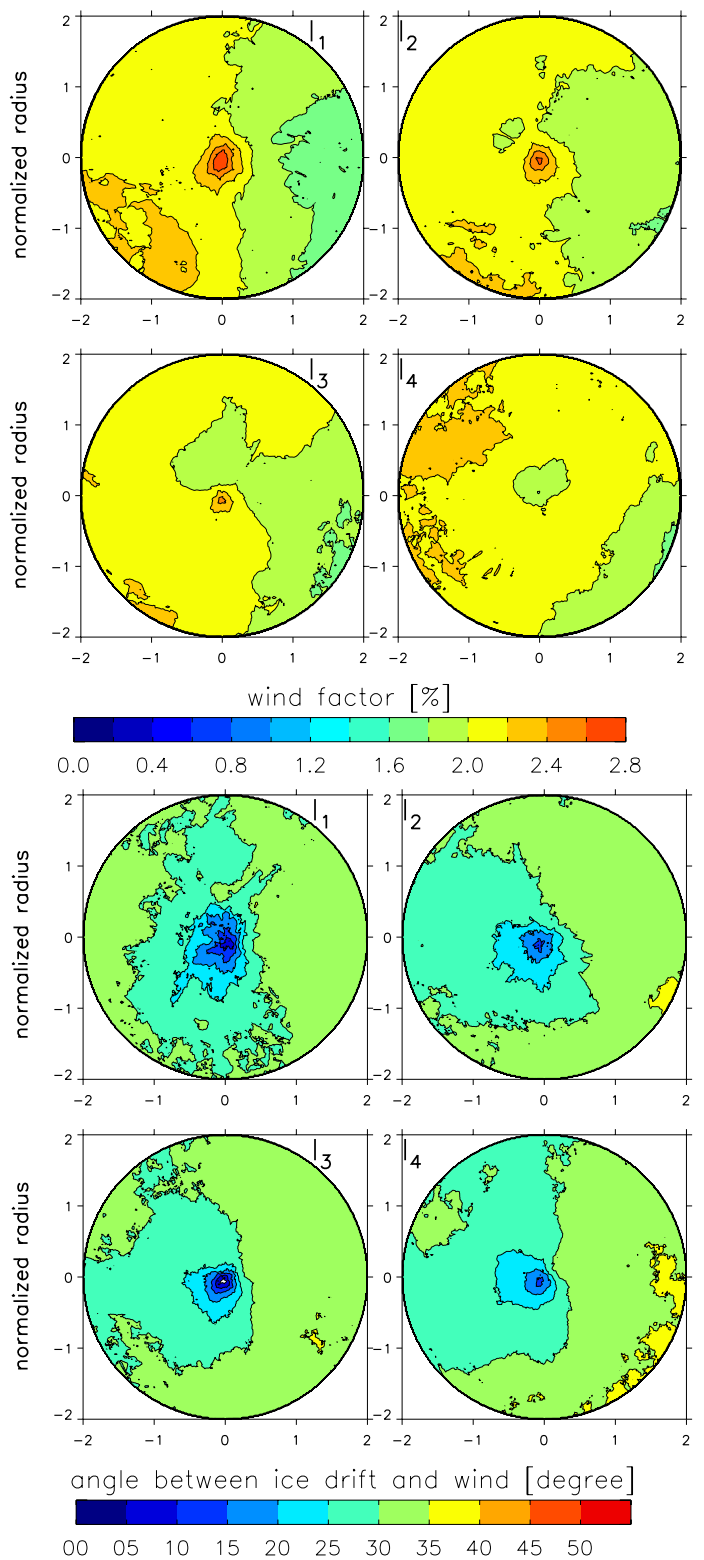

Fig. 4. Mean wind factor (top) and mean angle between wind forcing and ice drift (bottom) for the cyclone intensity classes $I_{1}$ to $I_{4}$. Isoline interval is $0.2 \%$ for wind factor and $5^{\circ}$ for deviation angle.

in ice concentration is stronger than in the other three classes. Altogether, AMSR-E observations support the model results that the ice concentration is reduced within the radius of the detection and that the ice reduction increases with increasing cyclone intensity.

Ice concentration is changed by two processes: divergence and deformation. In Fig. 7 the composite fields of vorticity, divergence, and shear deformation for the weakest and the strongest intensity classes, $I_{1}$ and $I_{4}$, are displayed. Vorticity and divergence are about three times stronger for $I_{4}$ cyclones than for $I_{1}$-cyclones, with respect to both the mean
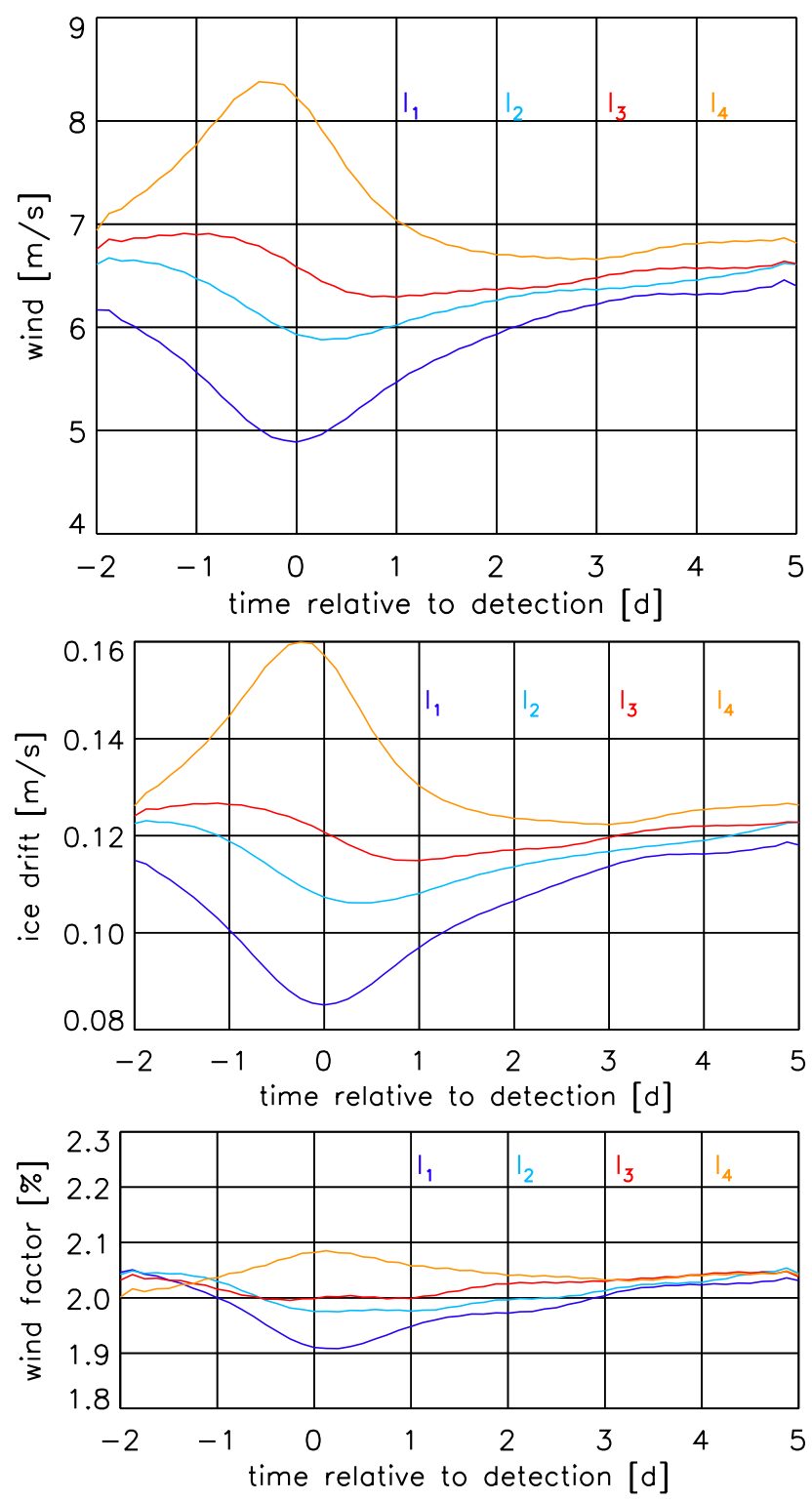

Fig. 5. Time series of wind (top), ice drift (middle), and wind factor (bottom) for different intensity classes. Shown are the mean values within the cyclone radius for the time period from 2 days before to 5 days after detection $(t=0)$.

values within the cyclone radius and the maximum values in the cyclone centre. The maximum vorticity in the centre of $I_{4}$-cyclones amounts to $22 \times 10^{-7} \mathrm{~s}^{-1}$ corresponding to a rotation of $11^{\circ}$ per day. The maximum divergence in $I_{4}$-cyclones amounts to $7.5 \times 10^{-7} \mathrm{~s}^{-1}$ corresponding to an opening of the ice by $5 \%$ per day. The shear deformation in $I_{1}$-cyclones is small whereas in $I_{4}$-cyclones maximum values of $15 \times 10^{-7} \mathrm{~s}^{-1}$ are reached. This means that a right angle opens by $7.5^{\circ}$ per day. Of course, these maximum values are not reached in the course of a day, because the composite fields do not remain for $24 \mathrm{~h}$ over the same location. The 

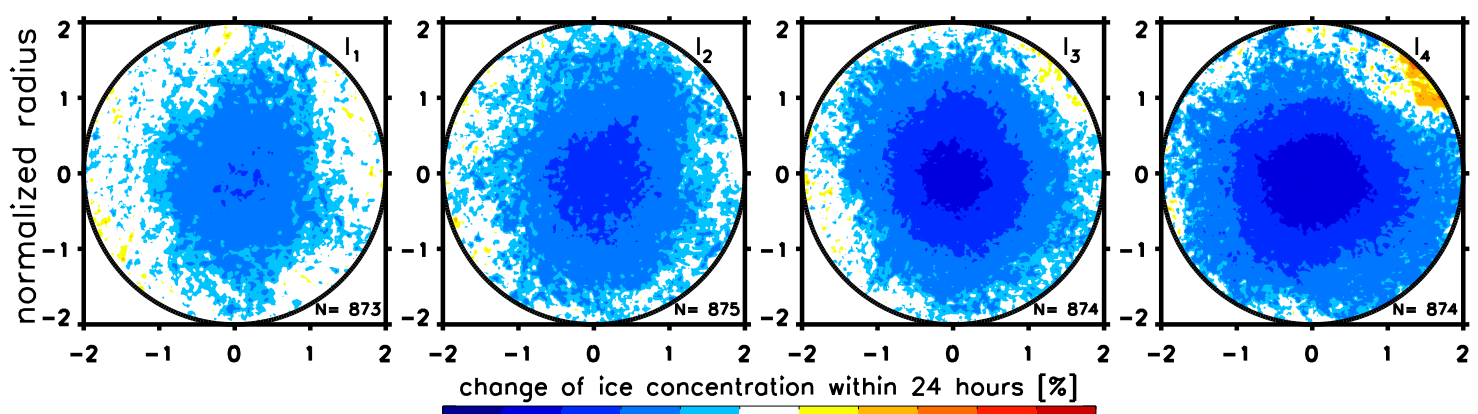

change of ice concentration within 24 hours [\%]

$\begin{array}{llllllllll}-2 & -1 & -0.5 & -0.2 & -0.1 & 0.1 & 0.2 & 0.5 & 1 & 2\end{array}$
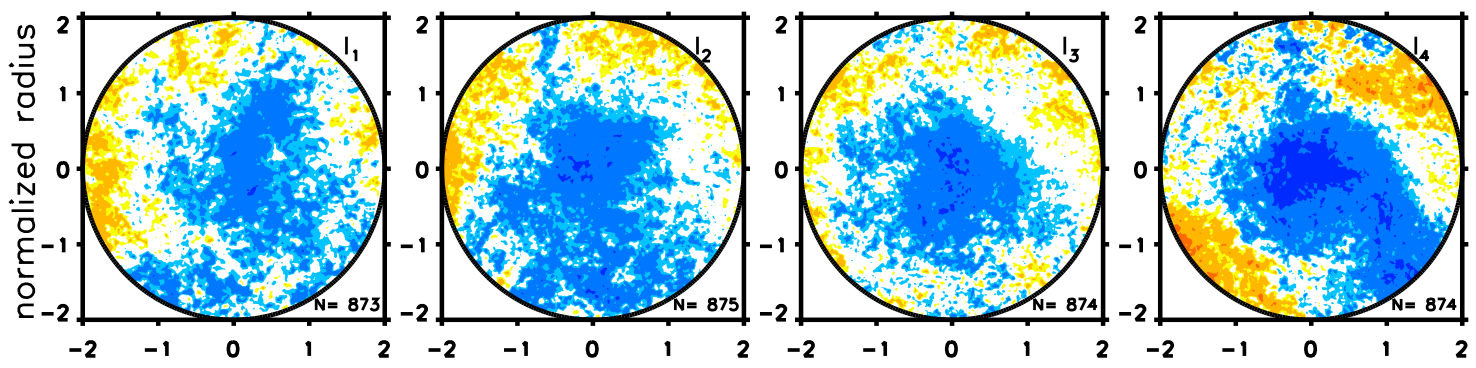

Fig. 6. Mean change of simulated (top) and AMSR-E (bottom) ice concentration within $24 \mathrm{~h}$ after cyclone passage $(t=0)$ for $I_{1}$ to $I_{4}$.

impact on vorticity, divergence, and deformation extends up to the cyclone radius for $I_{4}$-cyclones and is significant only in the very centre of the $I_{1}$-cyclones.

\subsection{Seasonal differences of cyclone impact}

The number of cyclone detections in the study area during the period 2006 to 2008 is almost the same in all seasons. Also in summer, the cyclone activity is high in the central Arctic. The maximum of cyclone detections is placed over the central Arctic Ocean in summer (Serreze and Barrett, 2008), while it is placed over the northeast Atlantic in winter (e.g. Sorteberg and Walsh, 2008). Due to the above-mentioned problem of ice concentration differences between AMSR-E and model in summer and autumn we use here only those detections where simulated and observed ice concentration are in the same range (Table 2). The frequency distribution of cyclone intensities in Fig. 8 shows a similar distribution in autumn (SON), winter (DJF), and spring (MAM), whereas the summer (JJA) cyclone intensity distribution has more weaker cyclones and less stronger cyclones. This ranking is also reflected in the season means in Table 2.

The composite cyclone wind fields for each season are presented in Fig. 9. As already mentioned for the intensity classes, the cyclonic wind field is not rotationally symmetric during autumn, winter, and spring but shows a maximum towards the negative $x$ and $y$ directions (i.e. towards the western Arctic because of the large-scale pressure increase from the Atlantic to the Pacific side of the Arctic). This is not the case in summer when the high-pressure zone over the western Arctic is absent. On the average, the wind is weaker in spring and summer than in autumn and winter as may be expected because of the more frequent weak summer cyclones. However, the differences are not large: the mean is $5.9 \mathrm{~m} \mathrm{~s}^{-1}$ in summer and $6.8 \mathrm{~m} \mathrm{~s}^{-1}$ in winter. This reflects the fact that the frequency distribution of cyclone intensities is not too much different between the seasons (Fig. 8). The ice-drift fields (not shown) exhibit an analogous pattern to the wind pattern, but have a different ranking of the seasons concerning mean drift speed. It is highest in autumn and lowest in summer and spring. This reflects a combination of the seasonal variations in wind speed and internal ice stress.

The composite fields of WF and DA around cyclones during different seasons are displayed in Fig. 10. The largescale gradients with decreasing WF and increasing DA towards the positive $x$ direction and slightly negative $y$ direction (i.e. towards the Canadian side) are, as was shown for the different cyclone intensities, also present in each season. This reflects the increasing ice thickness and, thus, increasing role of the Coriolis force towards the Canadian side. Figure 10 further represents the well-known observationally based seasonal differences of DA and WF. DA is in winter (average $29^{\circ}$ ) smaller than in summer (average $37^{\circ}$ ) and also WF is in winter (average $2.0 \%$ ) smaller than in summer. However, the largest WF values occur after summer, in autumn $(2.2 \%)$. This underlines the seasonally different importance of the internal ice stress. We remind that, according to the above-mentioned model-buoy comparison, the DA values may be slightly overestimated. But this does not affect the general seasonal and spatial patterns. The superposed cyclone effect with small DA and large WF (in accordance with a smaller mean ice thickness around the cyclone centre) 

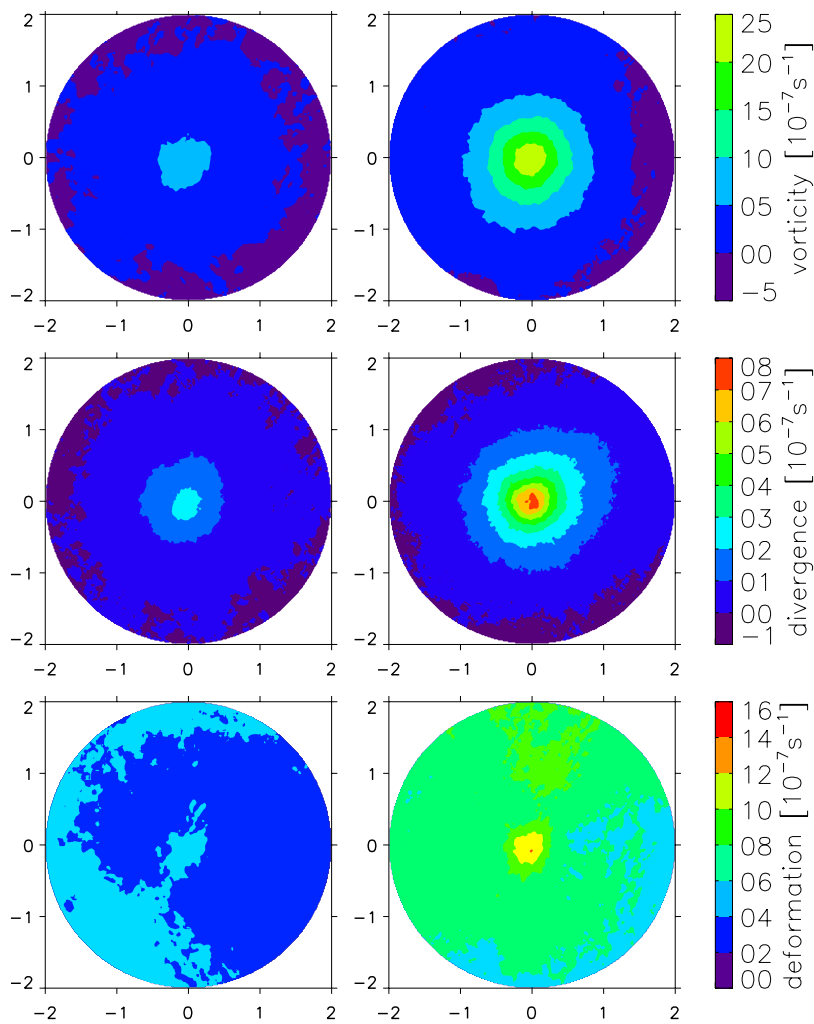

Fig. 7. Composite fields of vorticity (top), divergence (middle), and deformation (bottom) for intensity classes $I_{1}$ (left) and $I_{4}$ (right).

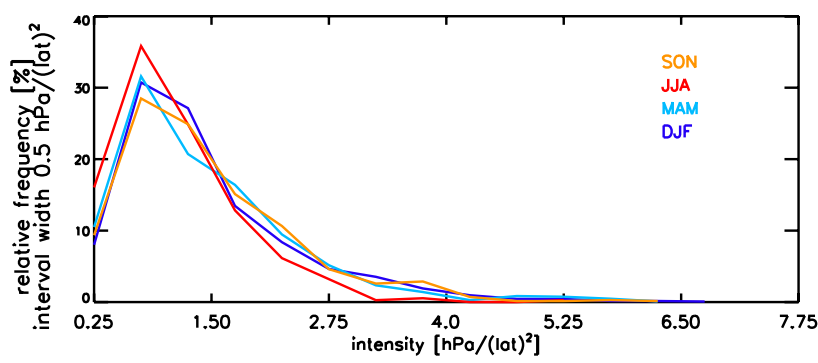

Fig. 8. Relative frequency of cyclone intensity per $0.5 \mathrm{hPa}$ (deg.lat.) ${ }^{-2}$ for each season.

is most obvious in winter and spring concerning both amplitude and extent. Though discernible, it is less distinct in summer. This results from the different mean ice concentrations in winter (about $98 \%$ ) and summer (about $77 \%$ ) (see Fig. 12). The change of the internal ice stress caused by the cyclone is less in case of a small rather than high ice concentration.

The seasonal impact of cyclones on the ice concentration during the first $24 \mathrm{~h}$ after the passage is shown in Fig. 11. In all seasons, a reduction is present which is most pronounced in spring and summer. In the centre of the cyclone the ice concentration is reduced within $24 \mathrm{~h}$ by $0.9 \%$ in winter, $1.7 \%$ in spring, $2.5 \%$ in summer and $1.2 \%$ in autumn.
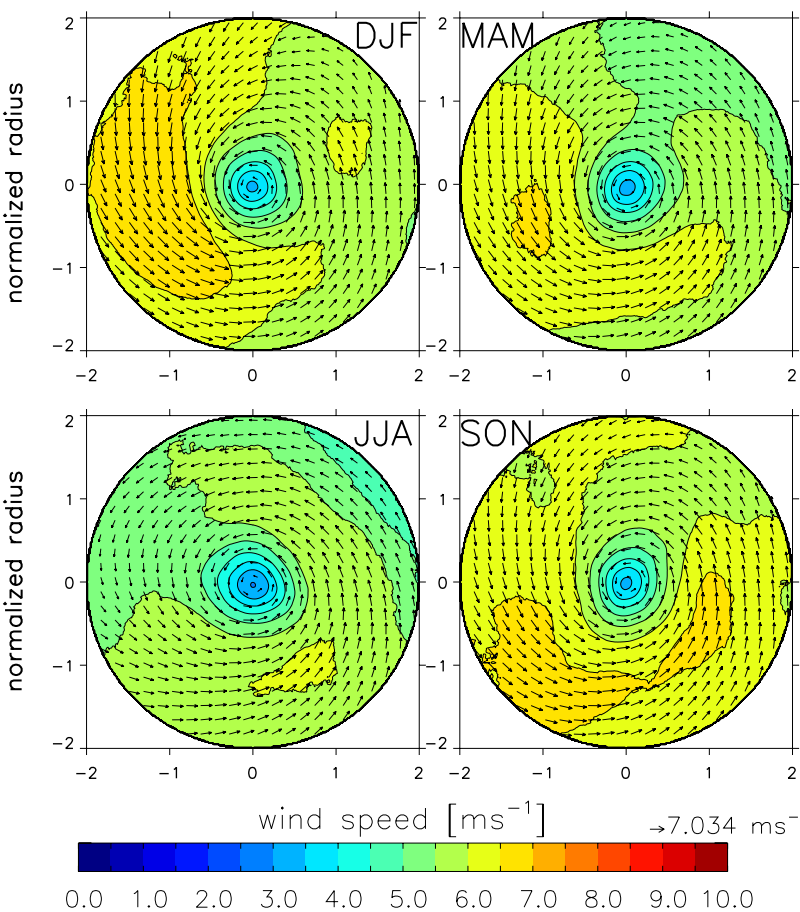

Fig. 9. Mean seasonal wind at the position of detection, normalized by radius. Shown are mean vector components and, as color, the mean value of wind speed. Isoline interval is $0.5 \mathrm{~m} \mathrm{~s}^{-1}$.

For a closer investigation of the cyclone-induced part of the ice concentration changes, the annual cycle of ice concentration has to be considered. Melting in summer and freezing in winter result in a long-term (longer than the cyclone event) decrease and increase of the sea-ice concentration, respectively. The cyclone impact is then superimposed on these seasonal trends, producing less of a decrease in concentration in winter than in summer. This effect can be seen in Fig. 11. The outer area (beyond 1.5 times the cyclone radius) shows no change in ice concentration in winter, a slight decrease in spring, a stronger decrease in summer, and an increase in autumn. For comparison, the $24 \mathrm{~h}$ change in the observed AMRS-E ice concentration is also shown in Fig. 11. The main features simulated by the model are also present in the satellite observations: cyclones reduce the ice concentration in all seasons. Outside the cyclone radius the mean seasonal trends of ice concentration are present: constant in winter, variable (decrease as well as increase) in spring, decrease in summer, and increase in autumn.

Figure 12 displays the temporal evolution of ice concentration within the cyclone radius in comparison to the ice concentration trend in the whole study area. In winter, temperatures are far below the freezing point and the ice concentration is high $(>98 \%)$. Open water, caused by cyclones, freezes quickly and the ice concentration has recovered $\approx 5$ days after the passage of the cyclone. In spring, the mean ice concentration is around $97 \%$. However, areas of 

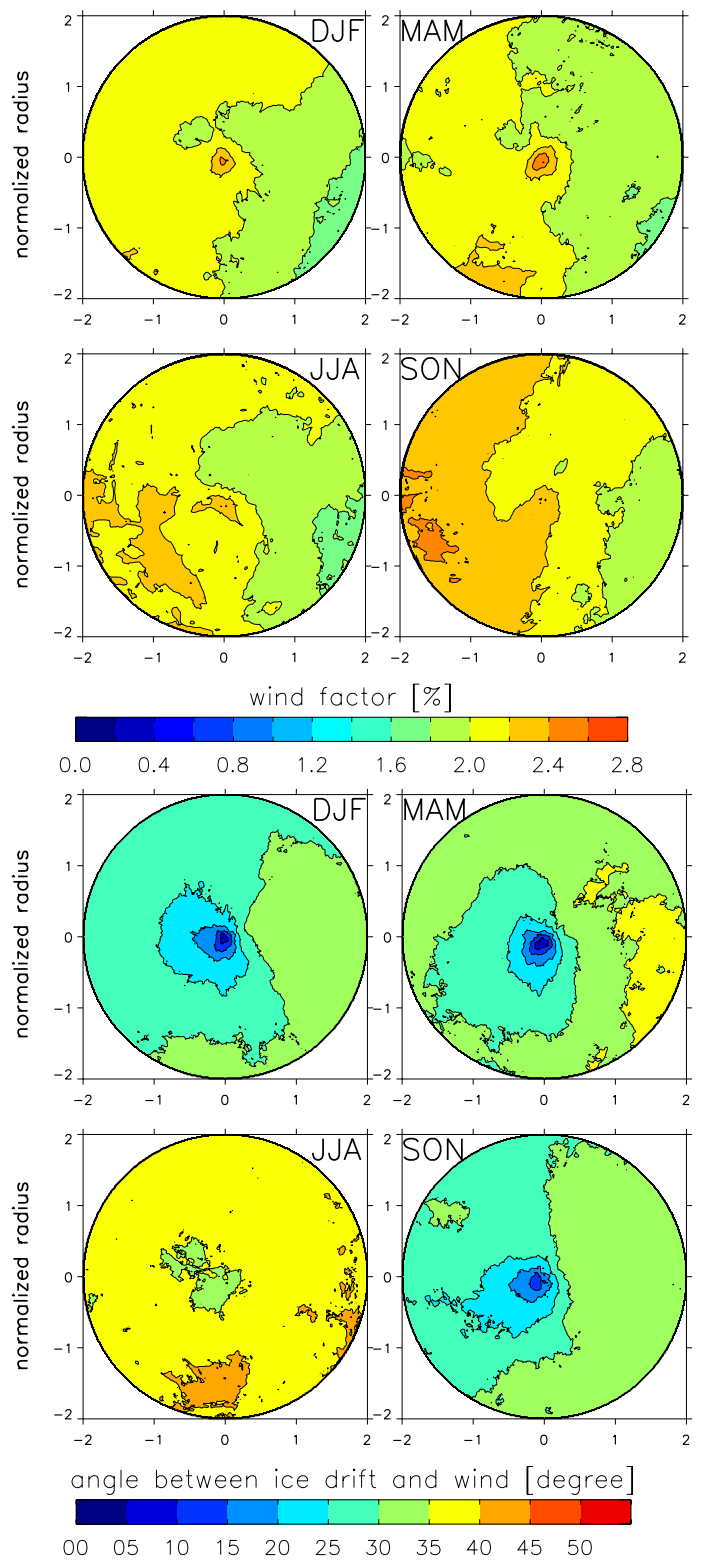

Fig. 10. Spatial distribution of the wind factor (top) and the angle between wind forcing and ice drift (bottom) for each season. Isoline interval is $0.2 \%$ for wind factor and $5^{\circ}$ for deviation angle.

open water, caused by cyclones, do not freeze as quickly as in winter. They exist even after a few days. The reason is the onset of the warming due to the solar radiation. In summer, the ice concentration is around $77 \%$ and is reduced by $2 \%$ per week even without cyclone impact. However, with cyclones the reduction is accelerated to $4 \%$ per week. In autumn, the mean ice concentration is about $83.5 \%$ and new ice is formed in large areas of the region. The ice concentration in the whole study area increases by about $2.5 \%$ per week. Under the influence of a cylone, the sea-ice concentration grows only by $1.5 \%$ per week. An important difference between the seasons is that the impact of a cyclone in winter is greatly diminished after about 5 days, whereas in the other seasons the impact remains visible. In summer, the difference between mean ice concentration in the whole study area and mean ice concentration within the area of detection is $2 \%$ even after 5 days. The cyclone-induced change in ice concentration relative to the mean seasonal trend underlines the quantitatively stronger reduction in summer (Fig. 12 bottom).

The seasonal difference in the duration of a cyclone's impact may have important climatological consequences. Many studies have examined the change in Arctic cyclone activity over the past decades, some finding an increase in the number of cyclones in the Arctic (e.g. Sepp and Jaagus, 2011). Zhang et al. (2004) found that the number of summer cyclones are increasing. With an increasing number of cyclones in summer, the melting of sea ice could be accelerated. This conclusion appears to be in contrast to the results of Screen et al. (2011), who find a positive correlation between Arctic sea-ice extent at the end of the summer and cyclone frequency in the preceding spring and summer. However, their investigation is on an Arctic-wide scale where other Arcticwide processes, like the strength of the Transpolar Drift, come into play, whereas our investigations are on the local cyclone scale. Of course, a cyclone in summer has two opposite effects. On one side, the cyclone breaks the ice and favors ice melt via the positive ice-albedo feedback. On the other side, a cyclone is related with a higher amount of clouds and reduces solar insolation and, thus, ice melting. However, both opposite effects are taken into account in the NAOSIM model, so the reason for the contradiction between our results and those of Screen et al. (2011) is not clear.

\subsection{Cyclone impact in different regions of the Arctic Ocean}

We divide the study area into four sub-regions: Siberian sector (Sib), Canadian sector (Can), North Pole region on the Siberian side (NP-S), and North Pole region on the Canadian side (NP-C) (Fig. 1). The regions were chosen in a way that all have similar numbers of detections (Table 2), but that the ice conditions differ. For example, in the Can sector thick and compact ice prevails moving with the Beaufort Gyre. The sea ice in the Sib sector is thinner and moves with the Transpolar Drift towards the Fram Strait. The mean intensity of cyclones is highest (see Table 2) in NP-S which is closest to the North Atlantic low-pressure zone (e.g. JahnkeBornemann and Brümmer, 2009), followed by Sib, NP-C, and finally Can which is close to the Arctic high pressure zone.

Figure 13 shows the frequency distribution of the wind factor WF at each model grid point within the cylone radius. In addition, the corresponding mean values of wind speed, ice concentration and thickness are listed. WF is highest in Sib where thin ice is present, followed by NP-S, NP-C, 

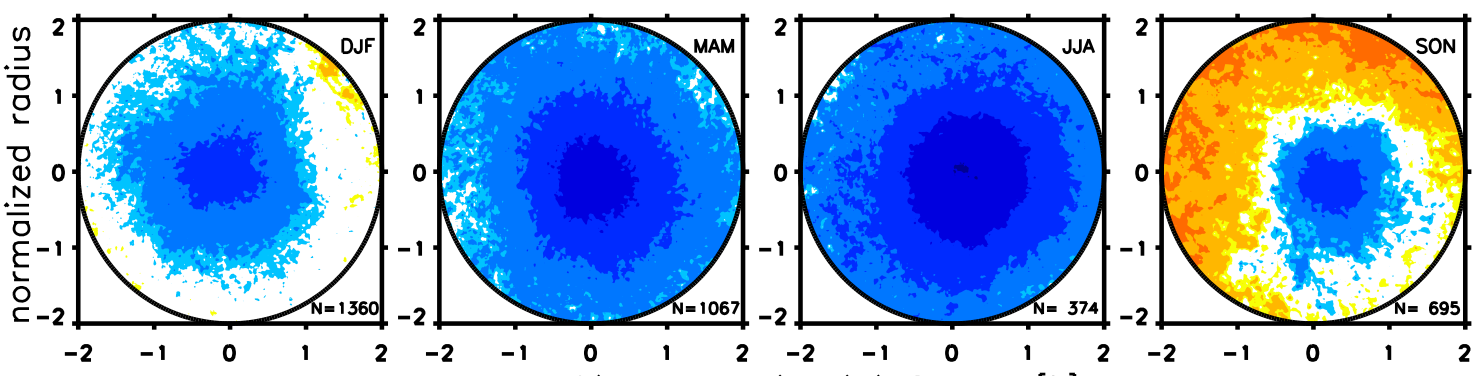

change of ice concentration within 24 hours [\%]

$\begin{array}{llllllllll}-2 & -1 & -0.5 & -0.2 & -0.1 & 0.1 & 0.2 & 0.5 & 1 & 2\end{array}$
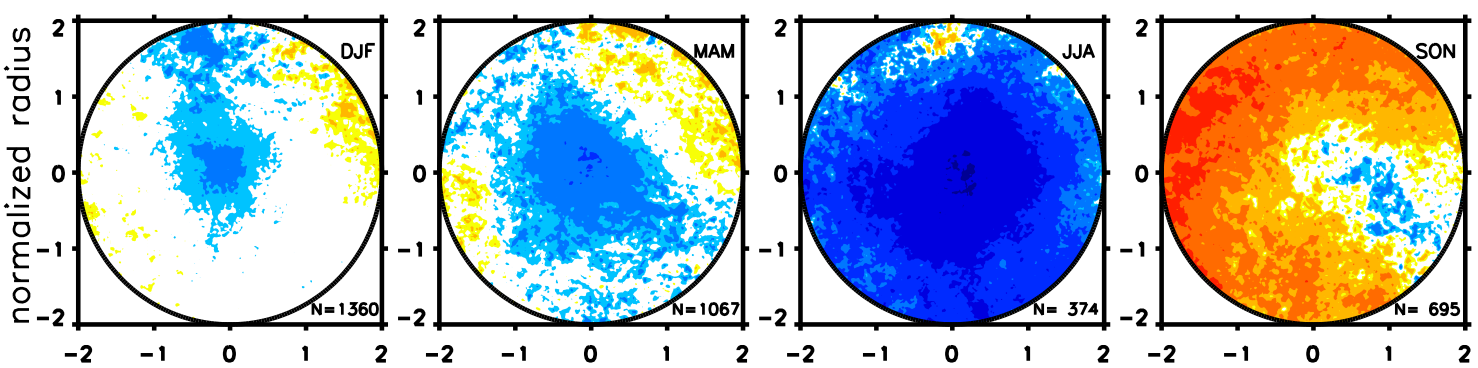

Fig. 11. Mean change of simulated (top) and AMSR-E (bottom) ice concentration within $24 \mathrm{~h}$ after cyclone passage $(t=0)$ for each season.

and Can where the thickest ice is present. Sectors Sib and NP-S are rather similar and so are the sectors Can and NPC. For NP-C and Can, there are relatively more grid-points within the cyclone radius with a small WF below $1.75 \%$. This is attributed to the thick (mean values $3.3 \mathrm{~m}$ and $4.2 \mathrm{~m}$, respectively) and compact ice (mean values $96 \%$ and $95 \%$, respectively) that piles up ahead of the Canadian Arctic Archipelago and that drifts relatively slow.

The mean deviation angle DA within the cyclone radius shows smaller values around $28^{\circ}$ in the Sib region and larger values around $35^{\circ}$ in the Can region (not shown). Thicker ice (larger Coriolis force) causes an increase of DA and more compact ice (larger internal ice stress) a decrease of DA. Obviously, the effect of ice thickness dominates over the effect of ice concentration when looking at the Sib-Can differences.

Time variations of wind, drift, and wind factor WF in the cyclone radius during a 7 day period around the cyclone passage $(t=0)$ within the four sub-regions are shown in Fig. 14. Wind speeds in the regions Can and NP-C are nearly identical and are the smallest, compared to the other regions. Wind speed in the Sib sector is slightly higher. In these three regions, the wind speed varies similarly with time, whereas in NP-S not only the wind speed is highest, but also the wind extremes occur at other times and the minimum is less distinct. The mean ice drift during a cyclone event is slowest in the Can and NP-C regions. The fastest moving ice can be found in NP-S, where the wind is strongest. The different WF levels between the Can-NP-C sectors on one side and Sib-NP$\mathrm{S}$ sectors on the other side are, as already mentioned above, due to the clearly different ice conditions (thickness, concen- tration). Furthermore striking is the opposite time variation of WF around the cyclone passage between Can-NP-C and Sib-NP-S. In Sib-NP-S, the passage is connected with an increase of WF by up to $0.1 \%$. In contrast to that, in CanNP-C WF decreases by up to $0.2 \%$. We presume that this is a consequence of the different climatological ice drift and ocean current systems on the Can and Sib side. In the Can sector, mean drift and current rotate anticyclonically with the Beaufort Gyre, whereas a cyclone rotates cyclonically. Thus, the atmospheric cyclone impact on the ice drift is reduced. In contrast to that, mean drift and current in Sib follow with the weakly cyclonically curved Transpolar Drift Stream. Thus, the cyclone impact on ice drift is supported and increases WF.

The time series of ice concentration within the cyclone radius show that the mean ice concentration 2 days before the detection starts at different levels between $91.5 \%$ in Sib and $97 \%$ in NP-C (Fig. 15 top). In all regions, the ice concentration 5 days after detection is reduced, compared to the mean ice concentration in the whole study area, and is below the value it had before the cyclone passage. Relating the ice concentration to that before the cyclone passage $(t=-2 \mathrm{~d})$ (Fig. 15 bottom), there is a similar development of the ice concentration in all regions. The reduction amounts between $1 \%$ and $1.5 \%$. The maximum cyclone-related ice reduction is reached about 1 day after the cyclone passage. 

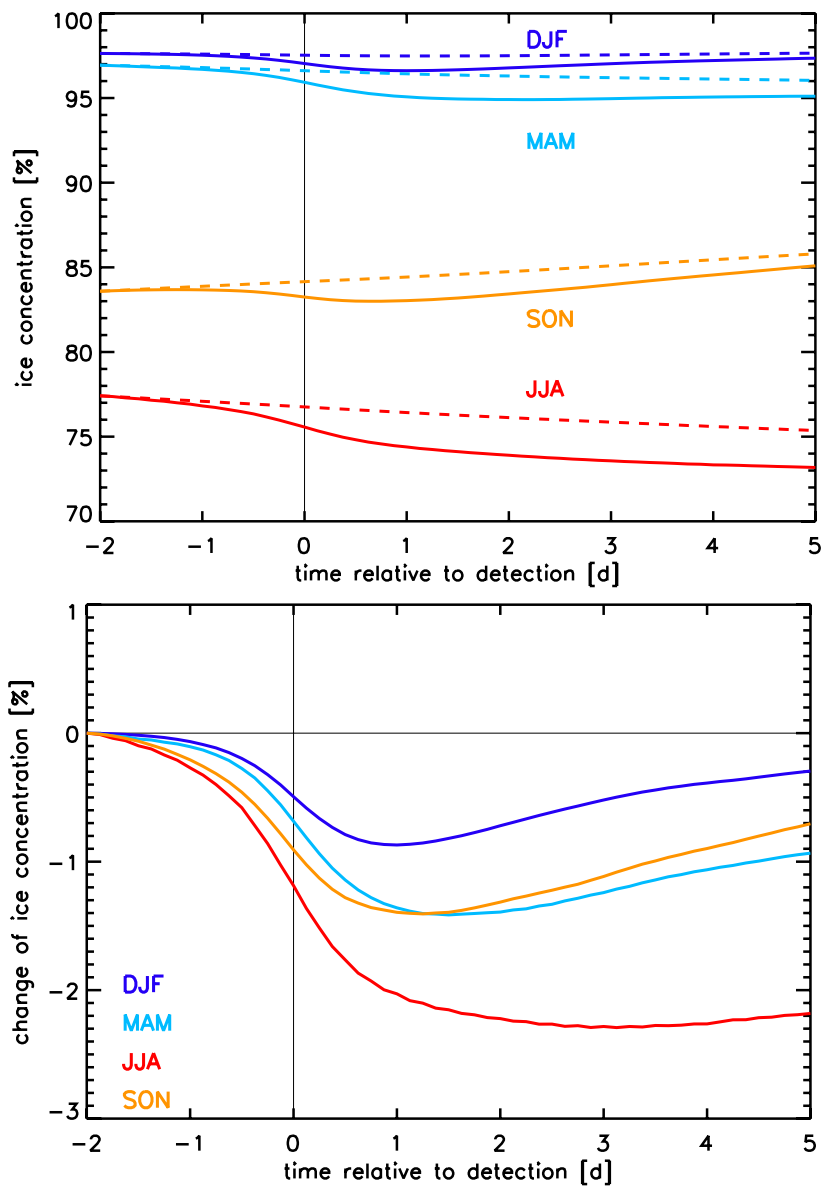

Fig. 12. Top: ice concentration in the period around the time of detection $(t=0)$. Solid line: mean over all detections within the cyclone radius, dashed line: simultaneous ice concentration in the whole study area (shifted to the starting value of the corresponding ice concentration within the cyclone radius). Bottom: detrended change in ice concentration, relatively to $t=-2 \mathrm{~d}$.

\section{Conclusions}

In this study the impact of cyclones on the sea ice in the central Arctic Ocean was investigated, in contrast to many case studies, for the first time in a statistical manner. To this end we applied the coupled ice-ocean model NAOSIM and forced it with the 6-hourly ECMWF analysis data for the period 2006-2008. Cyclone position and radius detected from the ECMWF sea-level pressure were used to extract the local fields of wind, ice drift, and concentration within twice the cyclone radius for a time interval from 2 days before to 5 days after the cyclone passage. The cyclone impact is quantified by the drift-wind ratio, the deviation angle, and the change of ice concentration. Centred at the cyclone position and normalized by the cyclone radius, composite fields of these quantities are calculated for different cyclone intensities, the four seasons, and different sub-regions of the Arctic Ocean.

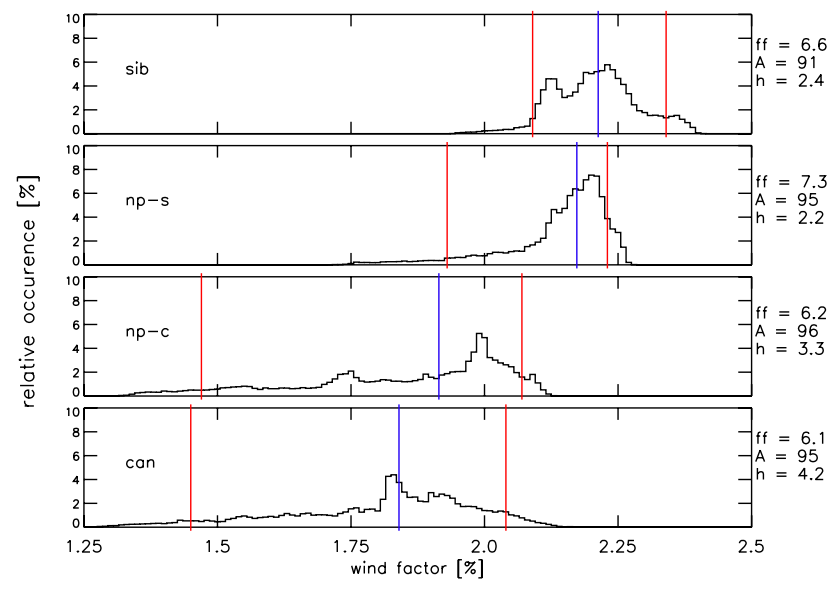

Fig. 13. Frequency distribution of the wind factor within the cyclone radius in four sub-regions of the Arctic Ocean. Red lines mark 5 and 95 percentiles, blue line marks the median. Also given is the mean wind speed $\mathrm{ff}[\mathrm{m} / \mathrm{s}]$, the mean ice concentration $A[\%]$ and the mean ice thickness $h[\mathrm{~m}]$.

The classification of the cyclones according to their intensities shows that wind speed and ice drift increase with increasing intensity. In general, the cyclone passage leads to a reduction of the ice concentration. The reduction increases from the cyclone edge to the centre. In the centre, the reduction within $24 \mathrm{~h}$ after the passage is of the order of 0.5 to $2 \%$ increasing with cyclone intensity. This spatial distribution and ranking of the ice concentration change is supported by independent AMSR-E satellite data.

Mean wind speed and ice drift within the cyclone radius show only small seasonal differences with a minimum in summer and a maximum in autumn/winter. The deviation angle between $10 \mathrm{~m}$-wind and ice drift is largest in summer with up to $37^{\circ}$ and smallest in autumn/winter with up to $29^{\circ}$. The wind factor has a minimum in spring and a maximum in autumn. Reductions in sea-ice concentration occur in all seasons, but with different magnitude and duration. The largest reduction of up to $4 \%$ occurs in summer and is persistent. In winter, the sea-ice concentration returns to its initial value a few days after the passage of a cyclone, because areas with open water refreeze quickly.

The regional investigation of cyclone impact reveals that wind speed and ice drift are strongest in the NP-S region, which is close to the North Atlantic cyclone track, and are weakest in the Can region, which is close to the high pressure zone over the western Arctic Ocean. The wind factor is smallest in the Can region with $1.8 \%$ and largest in the Sib region with $2.2 \%$. The main reason for the regional differences of cyclone impact is the different ice thickness and concentration in these sectors.

On the short timescale (less than $12 \mathrm{~h}$ ) of a passing cyclone, freezing and melting play a minor role in the change of ice concentration. Thus, the cyclone-induced reduction of 

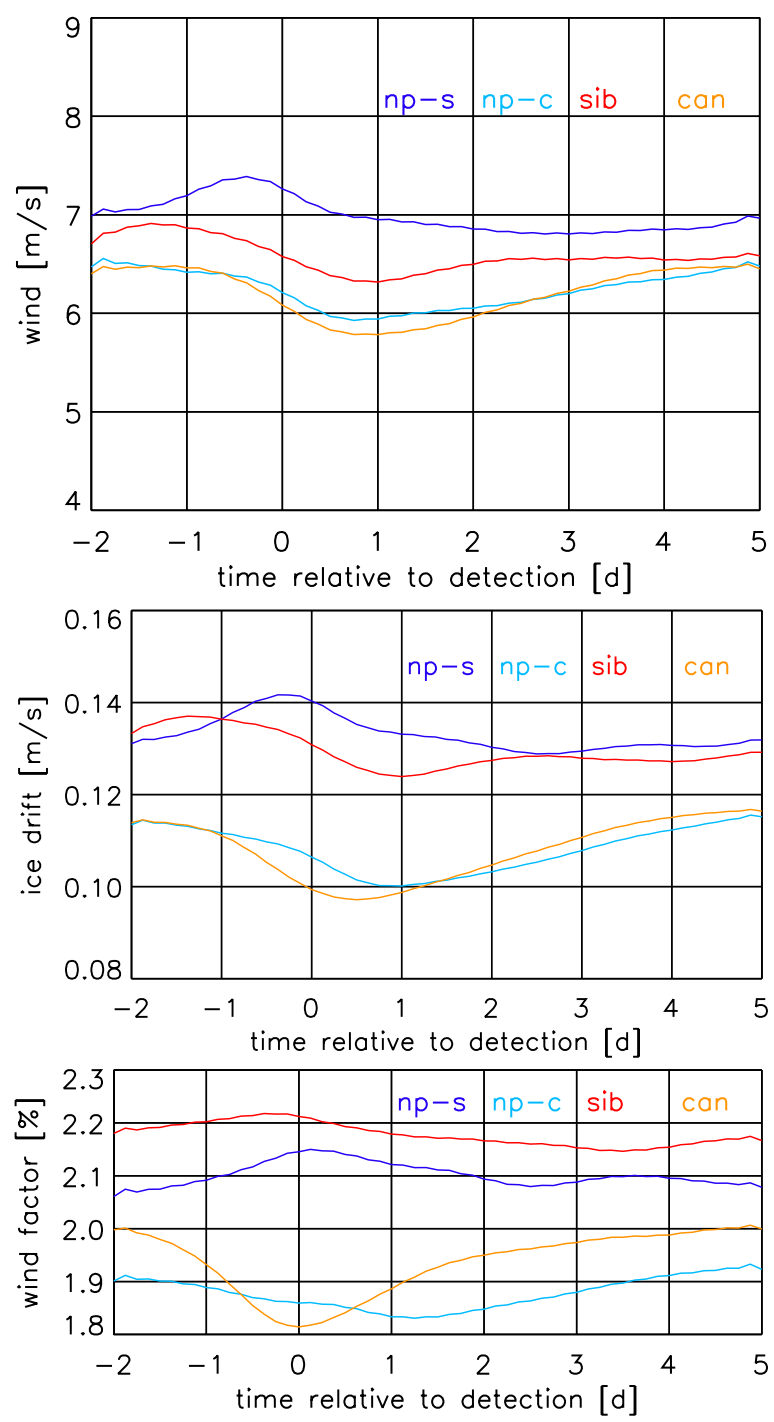

Fig. 14. As in Fig. 5, but for different sub-regions of the Arctic Ocean.

ice concentration is almost solely due to the dynamics (i.e. ice-drift divergence and ice sheet deformation). This means that there is no loss of ice mass. The subsequent processes of freezing and melting have different longer term or even climatologic consequences, especially in winter and summer. In winter, the heat flux between ocean and atmosphere over the cyclone-induced open water areas is increased for a few days. This heats and moistens the shallow Arctic boundary layer. At the same time the freezing of the open water areas leads to the formation of new sea ice, so that a further important impact of the wintertime cyclones is an increase of the Arctic ice mass. In summer, the cyclone-induced reduction of sea-ice concentration is largest and the open water areas remain open, decreasing the area average surface albedo and increasing the solar absorption. This summertime impact is expected to be especially large in areas with thinner ice as,
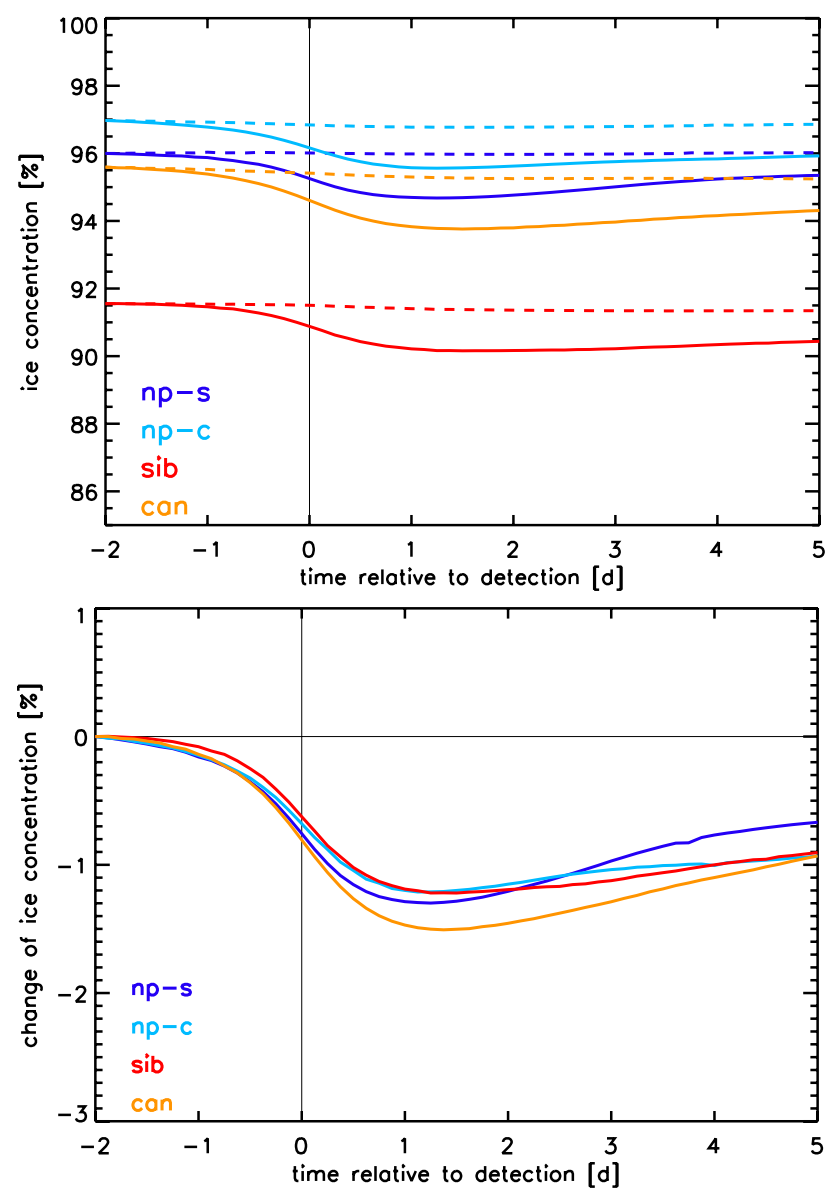

Fig. 15. As in Fig. 12, but for different sub-regions of the Arctic Ocean.

for example, on the Siberian side and in areas with smaller ice floes as, for example, in the marginal ice areas of the Arctic Ocean. Strong summer storms in those areas can lead to increased exceptional reduction of the sea-ice concentration, because they can separate and disperse large ice fields from the main Arctic ice cover. The strong summer cyclone between 4 and 8 August 2012 is believed to be one reason for the following record ice extent minimum in September 2012 (Simmonds and Rudeva, 2012). Based on model simulations, Zhang et al. (2013) hint at another impact of the strong 2012 August storm. They found an exceptionally strong bottom melt of the sea ice resulting from the cyclone-induced enhanced upward mixing of water from the near sub-surface ocean maximum temperature layer.

In this paper, we distinguished between three categories (intensity, season, region). This stratification can only show tendencies. A combined stratification would have been better and more instructive, but was not made here because of the only 3 year-long investigation period and the consequently limited number of cases. This could be improved with a longer investigation period. The cyclone radius may 
be a further classification parameter. Uotila et al. (2011) studied the relationship between cyclone properties and surface properties in the Antarctic. They distinguished between mesoscale $(r \leq 500 \mathrm{~km})$ and synoptic-scale cyclones $(r>$ $500 \mathrm{~km})$ and found that cyclones impacting the surface are more synoptic-scale and cyclones being impacted by the surface are more mesoscale. A further stratification criterion when applying the compositing method should be the propagation direction of the cyclone. Haapala et al. (2005) and Kriegsmann (2011) demonstrated that the cyclone impact is not symmetrical on the left and right side with regard to the propagation direction. On the right side, the cyclone presses the ice towards the not yet impacted ice cover, and away from it on the left side. All these additional stratification criteria would help to increase our knowledge of cyclone impact on sea ice, however, this requires a far larger number of cases.

Acknowledgements. This work was mainly supported by the European Union through the 6th framework programme with the Integrated Project DAMOCLES. Some support was obtained through the Cluster of Excellence "CliSAP" (EXC177), established at the University of Hamburg and funded by the German Science Foundation (DFG). We thank the editor of TC, O. Persson, for his constructive comments.

Edited by: O. Persson

\section{References}

Affeld, B.: Zyklonen in der Arktis und ihre Bedeutung für den Eistransport durch die Framstraße, Ph.D. thesis, Meteorologisches Institut, Universität Hamburg, available at: http://ediss.sub. uni-hamburg.de/volltexte/2003/1009 (last access: 26 February 2014), 2003.

Barry, R. G. and Maslanik, J.: Arctic sea ice characteristics and associated atmosphere - ice interactions in summer inferred from SMMR sata and drifting buoys: 1979-1984, GeoJournal, 18, 3544, 1989.

Blender, R., Fraedrich, K., and Lunkeit, F.: Identification of cyclone-track regimes in the North Atlantic, Q. J. Roy. Meteor. Soc., 123, 727-741, 1997.

Brümmer, B. and Hoeber, H.: A mesoscale cyclone over the Fram Strait and its effects on sea ice, J. Geophys. Res., 104, 1908519098, 1999.

Brümmer, B., Müller, G., and Hoeber, H.: A Fram Strait cyclone: Properties and impact on ice drift as measured by aircraft and buoys, J. Geophys. Res., 108, 4217, doi:10.1029/2002JD002638, 2003.

Brümmer, B., Schröder, D., Müller, G., Spreen, G., JahnkeBornemann, A., and Launiainen, J.: Impact of a Fram Strait cyclone on ice edge, drift, divergence, and concentration: Possibilities and limits of an observational analysis, J. Geophys. Res., 113, C12003, doi:10.1029/2007JC004149, 2008.

Curry, J., Schramm, J., and Ebert, E.: Impact of clouds on the surface radiation balance of the Arctic Ocean, Meteorol. Atmos. Phys., 51, 197-217, doi:10.1007/BF01030494, 1993.
Haapala, J., Lönnroth, N., and Stössel, A.: A numerical study of open water formation in sea ice, J. Geophys. Res., 110, C09011, doi:10.1029/2003JC002200, 2005.

Haller, M.: Arktische Zyklonen und Meereisdrift während der DAMOCLES-Bojenexperimente 2007-2010, Ph.D. thesis, Meteorologisches Institut, Universität Hamburg, 212 pp., available at: http://ediss.sub.uni-hamburg.de/volltexte/2011/5283 (last access: 26 February 2014), 2011.

Harder, M.: Dynamik, Rauhigkeit und Alter des Meereises in der Arktis - numerische Untersuchungen mit einem großskaligen Modell, Ph.D. thesis, Berichte zur Polarforschung, 203, Univ. Bremen, 129 pp., 1996.

Hibler, III., W.: A dynamic thermodynamic sea ice model, J. Phys. Oceanogr., 9, 815-846, 1979.

Hibler III., W.: The role of sea ice dynamics in modeling $\mathrm{CO}_{2}$ increases., Climate Processes and Climate Sensitivity, Geoph. Monog. Series, 29, 238-253, 1984.

Holt, B. and Martin, S.: The effect of a storm on the 1992 summer sea ice cover of the Beaufort, Chukchi, and East Siberian Seas, J. Geophys. Res., 106, 1017-1032, 2001.

Intrieri, J. M., Fairall, C. W., Shupe, M. D., Persson, P. O. G., Andreas, E. L., Guest, P. S., and Moritz, R. E.: An annual cycle of Arctic surface cloud forcing at SHEBA, J. Geophys. Res.Oceans, 107, 8039, doi:10.1029/2000JC000439, 2002.

Jahnke-Bornemann, A.: Zyklonen im Europäischen Nordmeer und Zusammenhänge mit der nordatlantischen Tiefdruckrinne, Ph.D. thesis, Meteorologisches Institut, Universität Hamburg, available at: http://ediss.sub.uni-hamburg.de/volltexte/2010/4494 (last access: 26 February 2014), 2010.

Jahnke-Bornemann, A. and Brümmer, B.: The Iceland-Lofotes pressure difference: different states of the North Atlantic low-pressure zone, Tellus A, 61, 466-475, 10.1111/j.16000870.2009.00401.x, 2009.

Karcher, M., Kauker, F., Gerdes, R., Hunke, E., and Zhang, J.: On the dynamics of Atlantic Water circulation in the Arctic Ocean., J. Geophys. Res., 112, C04S02, doi:10.1029/2006JC003630, 2007.

Kawaguchi, Y. and Mitsudera, H.: A numerical study of ice-drift divergence by cyclonic wind with a Lagrangian ice model, Tellus A, 60, 789-802, doi:10.1111/j.1600-0870.2008.00321.x, 2008.

Köberle, C. and Gerdes, R.: Mechanisms Determining the Variability of Arctic Sea Ice Conditions and Export, J. Climate, 16, 2843-2858, doi:10.1175/15200442(2003)016<2843:MDTVOA>2.0.CO;2, 2003.

Kriegsmann, A.: Einfluss von Zyklonen auf das Meereis in der zentralen Arktis: Modellstudien und Beobachtungen, Ph.D. thesis, Universität Hamburg, Von-Melle-Park 3, 20146 Hamburg, available at: http://ediss.sub.uni-hamburg.de/volltexte/ 2011/5257 (last access: 16 February 2014), 2011.

Lammert, A., Brümmer, B., and Kaleschke, L.: Observation of cyclone-induced inertial sea-ice oscillation in Fram Strait, Geophys. Res. Lett., 36, L10503, doi:10.1029/2009GL037197, 2009.

Leppäranta, M.: The Drift of Sea Ice, Springer Verlag, Berlin, Germany, 266 pp., 2005.

Martin, T. and Gerdes, R.: Sea ice drift variability in Arctic Ocean Model Intercomparison Project models and observations., J. Geophys. Res., 112, C04S10, doi:10.1029/2006JC003617, 2007. 
Maslanik, J. A. and Barry, R.: Short-term interactions between atmospheric synoptic conditions and sea-ice behaviour in the Arctic, Ann. Glaciol., 12, 113-117, 1989.

Maslanik, J. A., Fowler, C., Heinrichs, J., Barry, R., and Emery, W. J.: Remotely-sensed and simulated variability of Arctic seaice concentrations in response to atmospheric synoptic systems, Int. J. Remote Sens., 16, 3325-3342, 1995.

Murray, R. J. and Simmonds, I.: A numerical scheme for tracking cyclone centers from digital data. Part I: Development and operation of the scheme., Aust. Meteorol. Mag., 39, 155-166, 1991.

Notz, D. and Marotzke, J.: Observations reveal external driver for Arctic sea-ice retreat, Geophys. Res. Lett., 39, L08502, doi:10.1029/2012GL051094, 2012.

Overland, J. E. and Turet, P.: Variability of the atmospheric energy flux across $70^{\circ} \mathrm{N}$ computed from the GFDL data set, in: Nansen Centennial Volume, Geophys. Monogr., 84, 313-325, American Geophysical Union, 1994.

Perovich, D. K., Richter-Menge, J. A., Jones, K. F., and Light, B.: Sunlight, water, and ice: Extreme Arctic sea ice melt during the summer of 2007, Geophys. Res. Lett., 35, L11501, doi:10.1029/2008GL034007, 2008.

Rozman, P., Hölemann, J. A., Krumpen, T., Gerdes, R., Köberle, C., Lavergne, T., Adams, S., and Girard-Ardhuin, F.: Validating satellite derived and modelled sea-ice drift in the Laptev Sea with in situ measurements from the winter of 2007/08, Polar Res., 30, 7218, doi:10.3402/polar.v30i0.7218, 2011.

Screen, J. A., Simmonds, I., and Keay, K.: Dramatic interannual changes of perennial Arctic sea ice linked to abnormal summer storm activity, J. Geophys. Res., 116, D15105, doi:10.1029/2011JD015847, 2011.

Sepp, M. and Jaagus, J.: Changes in the activity and tracks of Arctic cyclones, Clim. Change, 577-595, 2011.

Serreze, M. and Barry, R. G.: The Arctic Climate System, Cambridge University Press, 385 pp., 2005.
Serreze, M. C. and Barrett, A. P.: The Summer Cyclone Maximum over the Central Arctic Ocean, J. Climate, 21, 1048-1065, 2008.

Simmonds, I. and Rudeva, I.: The great Arctic cyclone of August 2012, Geophys. Res. Lett., 39, L23709, doi:10.1029/2012GL054259, 2012.

Sorteberg, A. and Walsh, J.: Seasonal cyclone variability at $70^{\circ} \mathrm{N}$ and its impact on moisture transport into the Arctic, Tellus A, 60, 570-586, doi:10.1111/j.1600-0870.2008.00314.x, 2008.

Spreen, G., Kaleschke, L., and Heygster, G.: Sea ice remote sensing using AMSR-E 89-GHz channels, J. Geophys. Res., 113, C02S03, doi:10.1029/2005JC003384, 2008.

Stroeve, J. C., Kattsov, V., Barrett, A., Serreze, M., Pavlova, T., Holland, M., and Meier, W. N.: Trends in Arctic sea ice extent from CMIP5, CMIP3 and observations, Geophys. Res. Lett., 39, L16502, doi:10.1029/2012GL052676, 2012.

Thorndike, A. and Colony, R.: Sea Ice Motion in Response to Geostrophic Winds, J. Geophys. Res., 87, 5845-5852, 1982.

Ulbrich, U., Leckebusch, G., and Pinto, J.: Extra-tropical cyclones in the present and future climate: a review, Theor. Appl. Climatol., 96, 117-131, 2009.

Uotila, P., Vihma, T., Pezza, A. B., Simmonds, I., Keay, K., and Lynch, A. H.: Relationships between Antarctic cyclones and surface conditions as derived from high-resolution numerical weather prediction data, J. Geophys. Res., 116, D07109, doi:10.1029/2010JD015358, 2011.

Zhang, J., Lindsay, R., Schweiger, A., and Steele, M.: The impact of an intense summer cyclone on 2012 Arctic sea ice retreat, Geophys. Res. Lett., 40, 720-726, doi:10.1002/grl.50190, 2013.

Zhang, X., Walsh, J., Zhang, J., Bhatt, U., and Ikeda, M.: Climatology and Interannual Variability of Arctic Cyclone Activity: 1948-2002, J. Climate, 17, 2300-2317, 2004.

Zwally, H. J. and Walsh, J. E.: Comparison of observed and modeled ice motion in the Arctic Ocean, Ann. Glaciol., 9, 136-144, 1987. 